\title{
Knowledge Spillovers and TFP Growth Rates
}

\author{
Núria Quella* \\ Economics Department, Stony Brook University, \\ Stony Brook, NY 11794-4384, USA
}

April 2009

\footnotetext{
*E-mail address: nuria.quella@stonybrook.edu, Tel.: +1 631632 7534; fax: +1 6316327516 . I thank Boyan Jovanovic and Sílvio Rendon for useful suggestions, and Dale W. Jorgenson for his gracious provision of data. I am also indebted to participants in seminars at Banco de México, ITESM, CIDE, U. de Guanajuato, ITAM, the Midwest Macroeconomic Meetings in St. Louis, the Society for Economic Dynamics in Vancouver, the Society for Computational Economics in Montréal, and LACEA-LAMES in México City for helpful comments. The usual disclaimer applies.
} 


\begin{abstract}
In this paper I calibrate unobserved labor-generated knowledge spillovers within and between six large macroeconomic sectors covering the U.S. civilian economy from 1948 to 1991. Using quality-adjusted data I show that manufacturing and trade \& transportation are the main source of knowledge flows to the overall economy for the entire period. However, the productivity slowdown of the early seventies coincides with trade \& transportation taking over manufacturing as the main source and destination of post-73 knowledge flows. Furthermore, I compute the gap between the market and the optimal allocation of labor across sectors, and the wedge between market and optimal wages by sector. I find that, for the whole period, optimal employment in manufacturing and trade \& transportation is, respectively, $20 \%$ and $27 \%$ above market. As a result optimal output in these sectors is $12 \%$ and $16 \%$ higher than the market's, and optimal wages in manufacturing are $54 \%$ above market wages.
\end{abstract}

Keywords: Knowledge spillovers; productivity; human capital; learning; wages. JEL Classification: D24, J24, O30, O40. 


\section{Introduction}

Although spillovers have always had an important role in economic theory and policy design, the difficulties involved in their measurement have made their empirical computation far less popular.

In this paper I compute a matrix of unobserved labor-generated knowledge spillovers within and between six large macroeconomic sectors covering the whole U.S. civilian economy: manufacturing, mining, construction, services, trade \& transportation, and agriculture. ${ }^{1}$ I show that, from 1948 to 1991, manufacturing and trade \& transportation are undisputedly the leading knowledge generators for the whole U.S. economy. Moreover, I also compute the gap between the market and the optimal sectoral allocation of labor and its return rates. I find that efficiency requires the market to increase employment in manufacturing by $20 \%$ and in trade \& transportation by $27 \%$, so that output in these sectors increases by $12 \%$ and $16 \%$ respectively; and wages in all sectors, except for mining and trade \& trasnportation, increase by at least $54 \%$.

I also show that the productivity slowdown of the early seventies coincides with trade \& transportation taking over manufacturing as the main generator of knowledge spillovers to the whole economy and with increasing sectoral integration, that is, with spillovers within sectors declining in favor of spillovers between sectors.

Two bodies of literature have particularly concerned themselves with the magnitude of externalities: economic growth has focused on the role of externalities in generating long run growth; real business cycles research has used externalities to explain why total factor productivity (TFP) is procyclical once imperfect competition and increasing returns to scale proved insufficient to account for it. A third strand of work has concentrated on the imperfect measurement of output and inputs as a source of the erroneous measurement of productivity growth rates. This paper sits at the cross-roads of these three bodies of work.

\footnotetext{
${ }^{1}$ Because of data availability and/or quality, previous measurements of external economies refer to manufacturing.
} 
I start from a production theoretic framework and propose a static model, extendable to a dynamic setting. The model presents a multisector economy where the production function incorporates knowledge externalities in labor employed at all stages and levels of the production process. Knowledge spillovers in a particular industry are generated by the capacity of all employees to learn from their own and from others' productive experience. In other words, employees learn by observing as well as by doing. ${ }^{2}$ Arrow (1962) was among the first to consider the economic impact of learning from experience and to formally model spillovers of any kind. Furthermore, Lucas $(1988,1993)$ emphasized the centrality of learning on the job and its external effects as an engine of growth beyond specific production processes, that is, the importance of spillovers from learning by doing for entire economic sectors and economies and the supporting role of physical capital accumulation. ${ }^{3}$ More recently, Jovanovic and Rousseau (2002) have extended these arguments to the "new economy." Among others, Lieberman (1984), Cohen and Levinthal (1990), Young (1993), Jovanovic and Nyarko (1995), and Klenow (1998) have also worked along the same lines. ${ }^{4}$

In order to calibrate the parameters characterizing the model I use the database developed by Dale W. Jorgenson for the U.S. civilian economy from 1948 through 1991 containing quality-adjusted factor and product sectoral panel data. The use of this database allows me to distinguish between substitution among different types of inputs (with different combinations of marginal productivity in their components)

\footnotetext{
${ }^{2}$ Early on, Rapping (1965) applied data on the production of the Liberty Ship to a Cobb-Douglas production function within a neoclassical framework to illustrate the learning principle present in many other industries, namely that workers' performance of a task improves with increases in the repetition of that task, albeit decreasingly.

3 Benhabib and Jovanovic (1991) examine a variety of bodies of data within an augmented Solow model and show that aggregate data are not consistent with physical capital as the source of spillovers, leaving open the possibility that social increasing returns are caused by human capital instead; ideas come first, capital investment follows. Klump, McAdam and Willman (2007) use a CES production function to show that technical progress is purely labor augmenting in the long run while capital-augmenting progress fades away.

${ }^{4}$ Given the sectoral approach of this paper and its time scope, I fully abstract from consideration of geographic or agglomeration effects on knowledge spillovers. See Thompson (2006) for evidence that intranational localization effects become weaker with the passage of time.
} 
and growth in productivity. Often, what previous studies have called spillovers were really input quality improvements. Once input heterogeneity and quality changes are taken into account, the TFP term will only pick up the costless spillover effects.

The remainder of the paper is organized as follows. Next section describes a model with inter- and intra-industry labor generated knowledge spillovers and states the difference between the market and the optimal solution in terms of resource allocation and return to labor; Section 3 goes through the calibration choices necessary to measure these spillovers, including the dataset used and the literature of reference, and discusses the resulting matrix of knowledge flows. Section 4 reexamines the gap between the market and the optimal solution in light of the data. Section 5 explores the possibility of a shift in spillovers being associated with the productivity slowdown of the early seventies. Finally, Section 6 summarizes the paper's main conclusions.

\section{Model}

This section presents a multiple sector model where the production function incorporates knowledge externalities in labor. Consequently, while private returns to scale are constant, social returns are increasing. Knowledge spillovers in a particular sector stem from its own workers' skill level and productive experience (learning by doing), and from the quality of labor employed in all other sectors in the economy and what can be learnt from their experience (learning by observing).

Consider an economy consisting of $n$ sectors, each producing a differentiated final good $Y_{i}$ with capital $K_{i}$, labor $L_{i}$, and intermediate goods $M_{i}$. The production function at any given period is characterized by sectoral knowledge spillovers in labor, that is,

$$
Y_{i}=A_{i} K_{i}^{\beta_{i K}} L_{i}^{\beta_{i L}} M_{i}^{\beta_{i M}} \prod_{j=1}^{n} L_{j}^{\gamma_{i j}}, i=1,2, \ldots, n .
$$

The exogenous time-invariant scale factor $A_{i}$ is here unrelated to the input variables 
and, hence, there is no endogenous growth derived from it. ${ }^{5}$ The $L_{j}^{\gamma_{i j}}$ are sectoral spillovers that improve the marginal productivity of all inputs in the sector equally and costlessly. They are characterized by the learning parameters $\gamma_{i j} \geq 0$ that measure the extent to which sector $i$ learns from sector $j$. If $i=j$, they are called sector-specific or intra-sectoral knowledge spillovers; if $i \neq j$, they are inter-sectoral knowledge spillovers. All learning parameters are non-negative because un-learning from one's own or others' productive experience has no economic meaning. ${ }^{6}$

Every sector $i$ exhibits private constant returns to scale $\beta_{i K}+\beta_{i L}+\beta_{i M}=1$. Endowments are fully used: $K=\sum_{i=1}^{n} K_{i}, L=\sum_{i=1}^{n} L_{i}$, and $M=\sum_{i=1}^{n} M_{i}$. Sectoral production sumps up to the economy's output: $\sum_{i=1}^{n} Y_{i}=Y$, and the consumer's utility function is $U\left(C_{1}, C_{2}, \ldots, C_{n}\right)=\prod_{i=1}^{n} C_{i}^{\alpha_{i}}$, where $\sum_{i=1}^{n} \alpha_{i}=1$ and $\alpha_{i}>0 \forall i$.

Each sector $i$ receives total spillover $q_{i}=\sum_{j=1}^{n} \gamma_{i j}$ and emits total spillover $\Gamma_{i}=\sum_{j=1}^{n} \alpha_{j} \gamma_{j i}$. The economy-wide coefficient for each factor $X=K, L, M$ is $\beta_{X}=\sum_{j=1}^{n} \alpha_{j} \beta_{j X}$ and the economy-wide emission (and reception) of spillovers is $Q=\sum_{j=1}^{n} \alpha_{j} q_{j}=\sum_{i=1}^{n} \Gamma_{i}{ }^{7}$

Social returns to any sector are $1+q_{i}$ which, unless $q_{i}=0$, means there are really sectoral and, hence, economy-wide increasing returns to scale. ${ }^{8}$ Thus, TFP estimates will reflect the labor generated knowledge externality and, therefore, there will be a gap between the market's sectoral allocation of labor and its rate of return and what

\footnotetext{
${ }^{5} \mathrm{~A}$ dynamic extension of this model would have $A_{i}$ as a Hicksian neutral shift parameter: the scale factor $A_{i}$ would vary over time as the productivity of inputs and/or the knowledge spillovers change. In this model $A_{i}$ is the ratio of output to total factor input plus spillovers.

${ }^{6}$ Learning as a source of knowledge spillovers rules negative externalities out. Consider a simple sectoral production function with labor as the only factor of production and learning by doing $Y_{i}=f\left(N_{i}\right) Y_{i}^{\theta}$. The learning elasticity or slope of the learning curve is, for the sake of simplicity, a constant $0 \leq \theta<1$ and the learning effect $Y_{i}^{\theta}$ is bounded. With constant returns on the production function, $f\left(N_{i}\right)=N_{i}$, the previous expression can be rewritten as $Y_{i}=N_{i}^{\frac{1}{1-\theta}}$, where $\frac{1}{1-\theta} \geq 1$ and, therefore, $Y_{i} \geq f\left(N_{i}\right)$. Compare this form with a production function similar to the one in this model but with labor as the only input and no inter-sectoral externalities: $f\left(N_{i}\right)=N_{i}^{1+\gamma_{i i}}, \forall i$. Then $1+\gamma_{i i}=\frac{1}{1-\theta}$ or $\theta=\frac{\gamma_{i i}}{1+\gamma_{i i}}$. Thus, $0 \leq \frac{\gamma_{i i}}{1+\gamma_{i i}}<1$, and $0 \leq \gamma_{i i}$.

${ }^{7}$ Ultimately, the set of sectoral spillovers $q_{i}$ and the economy-wide spillover $Q$ will depend on the sectoral structure of the economy and its employment schedule.

${ }^{8}$ Note that sectoral private returns to spillover-generating $L_{i}$ are really $\beta_{i L}+\gamma_{i i}$ and social returns are $\beta_{i L}+\Gamma_{i}$
} 
is optimal.

The market sets a unique competitive return rate for each input

$$
w_{X}^{c}=\beta_{i X} \frac{P_{i} Y_{i}}{X_{i}}, X=K, L, M
$$

whereas the optimal wage rate is sector-specific: $w_{i}^{s} \neq w_{j}^{s}, \forall i \neq j$ and $\frac{w_{i}^{s}}{w^{c}}=\left(1+\frac{\gamma_{i i}}{\beta_{i L}}\right) \frac{Y_{1}^{s} / Y_{1}^{c}}{L_{i}^{s} / L_{i}^{c}}$, where $\frac{Y_{1}^{s} / Y_{1}^{c}}{L_{i}^{s} / L_{i}^{c}}$ is the optimal-to-market average product of labor ratio measured in units of the numeraire.

The market sectoral allocation of inputs is

$$
\frac{X_{i}^{c}}{X}=\frac{\alpha_{i} \beta_{i X}}{\beta_{X}}, X=K, L, M
$$

Because of Cobb-Douglas preferences and technology, planner and market allocate capital and intermediate goods the same way, but the planner will optimize the allocation of labor:

$$
\frac{L_{i}^{s}}{L}=\frac{\alpha_{i} \beta_{i L}+\Gamma_{i}}{\beta_{L}+Q}
$$

In principle, both the market and the planner respond to an increase in consumers' preferences for one good increasing labor allocated to its production. However, the planner also takes into consideration how much productive knowledge workers employed in each sector generate for the benefit of the overall economy. If employing more workers in a particular sector will generate more knowledge for the whole economy and, thus, make it more productive, the planner will allocate more workers to this sector than strictly determined by consumers' preferences and technological needs. That is,

Proposition 1 The planner allocates more labor than the market to sector $i, L_{i}^{s}>L_{i}^{c}$, iff $\frac{\Gamma_{i}}{Q}>\frac{L_{i}^{c}}{L}$. Similarly, $L_{i}^{s}<L_{i}^{c}$, iff $\frac{\Gamma_{i}}{Q}<\frac{L_{i}^{c}}{L}$ and $L_{i}^{s}=L_{i}^{c}$, iff $\frac{\Gamma_{i}}{Q}=\frac{L_{i}^{c}}{L}$. Proof: $L_{i}^{s} \lesseqgtr L_{i}^{c}$ if $\frac{\alpha_{i} \beta_{i L}+\Gamma_{i}}{\beta_{L}+Q} \lesseqgtr \frac{\alpha_{i} \beta_{i L}}{\beta_{L}}$ which is equivalent to $\frac{\Gamma_{i}}{Q} \lesseqgtr \frac{L_{i}^{c}}{L}$ 
This Proposition determines the sign of the efficiency gap for each sector, as will be seen in Section 4.

\section{Calibration}

In order to compute the magnitude and directionality of knowledge spillovers I must first determine the numerical value of the model's parameters. These values are set according to the data used and to estimates in previous literature, both discussed below.

\section{Data}

The panel dataset used in the calibration is an update on the original sectoral inputoutput database developed by Dale W. Jorgenson for the 1948-1979 period, also described in Jorgenson and Stiroh (2000), Jorgenson (1990), and Jorgenson, Gollop and Fraumeni (1987). It covers 35 sectors at roughly the 2-digit Standard Industrial Classification (SIC) 1987 level, that is, the whole of the U.S. civilian economy from 1948 to 1991. For each sector, it contains annual observations on the value and the price of output and four inputs (capital, labor, energy and material), quality-adjusted.

Because input growth reflects increases in input quantity as well as changes in input quality or marginal productivity, estimated TFP only captures the effect of costless spillovers. ${ }^{9}$ As a result computed TFP growth becomes smaller (Jorgenson and Griliches 1967).

Using the index number approach, I then compute sectoral input quantities and value added. Industrial value added is more advantageous than gross output measures because it always sums up to total value added (GDP), independently of the degree of vertical and horizontal integration and of the proportion of intermediate goods

\footnotetext{
${ }^{9}$ According to Jorgenson, Ho and Fraumeni (1994) about ten percent of the growth of the US economy in between 1947 and 1989 is due to increases in labor quality, which is the source of the spillover, but not the spillover itself.
} 
used. $^{10}$

\section{Grouping of Industries into Sectors}

To make results tractable, government enterprises are eliminated, and energy and material are consolidated into a single intermediate inputs category. The remaining 34 industries are then aggregated into six larger sectors following the division drawn by Long and Plosser (1983) when analyzing real business cycles: manufacturing $(M)$, mining $(N)$, construction $(C)$, services $(S)$, trade \& transportation $(T)$, and agriculture $(A)$. The interested reader can see the industrial composition of each sector in Appendix A1.

For each period $t$ I generate a five-year central moving average from original annual data. This, together with the fact that inputs in Jorgenson's dataset are measured in flows of services, rather than in stocks, reduces the unwanted short-term effects of business cycles (i.e. of changes in the rate of utilization of inputs) on the model's productivity estimates.

Aggregation of industries into a smaller number of sectors generates, on the one hand, an increase in the heterogeneity of the labor input, which the index number approach handles without difficulty and, on the other, an increase in the magnitude of sectoral spillovers $q_{i}$, as more sources of spillovers "pile up" in a given sector. ${ }^{11}$

\section{Consumers' Preferences}

The values of consumers' preferences for each sector, $\alpha_{i}$, are computed directly from the data:

$$
\alpha_{i}=\frac{Y_{i}}{Y}
$$

\footnotetext{
${ }^{10}$ Aggregate value-added is immune to the kind of aggregation bias that occurs when sectoral share-weights change with the reallocation of GDP among sectors with different TFP levels and growth rates, creating a path dependence problem for the aggregate productivity index. Moreover, value added is impervious to outsourcing.

${ }^{11}$ A sector's spillovers reflect the combined effect of spillovers within the individual industries and the induced effects on those industries of intermediate inputs produced themselves with markups or externalities and under increasing returns that pile up in aggregation.
} 
where $Y_{i}$ is the market demand for sector $i$ which, in this model, is equal to sector $i$ 's production, given $\sum_{i=1}^{n} \alpha_{i}=1$ and $\alpha_{i}>0 \forall i$.

Table 1 shows the numerical values of consumers' preferences and of all the model's calibrated parameters discussed below.

$$
\text { [Insert Table } 1 \text { here] }
$$

\section{Technology}

Output elasticities of inputs by sector, $\beta_{i X}$, are calibrated from the data's average between-period cost-shares of each input, $\bar{S}_{i X}, X=K, L, M$. I start by using index prices and index quantities to compute $\bar{S}_{i X}=w_{x_{i}} X_{i} / P_{i} Y_{i}$, where $w_{x_{i}}$ is the rate of return of input $X$ in sector $i$, and $P_{i}$ is the price of sector $i$ 's product. Given that under perfect competition and constant returns to scale output elasticities are equal to factor shares, I can safely assume $\beta_{i X}=\bar{S}_{i X}$, as seen in Appendix A2.

Table 1 shows the numerical values of output elasticities for each input by sector. For the overal economy, the elasticities of capital, labor, and intermediate goods are, respectively, $0.15,0.34$, and 0.50 .

\section{Magnitude and Ranking of Sectoral Spillovers}

The empirical estimation of external economies operating at the national and industry level can be traced back to Lucas (1988) and Hall (1988, 1990), respectively. Lucas estimated the external effects of human capital for the whole U.S. economy from 1909 to 1957 to be around 0.4. Hall measured the industry level externality for manufacturing from 1958 to 1981 around 0.3 .

Domowitz, Hubbard and Petersen (1988), Caballero and Lyons (1992), Baxter and King (1991), and Bartelsman, Caballero and Lyons (1991, 1994) all started from a Cobb-Douglas production function with perfect competition and constant returns to scale to explain the gap between manufacturing output growth and the growth of 
its inputs, labor in particular. And all came up with a manufacturing externality in between 0.3 and 0.4 .

These estimations set the range for the value of sectoral knowledge spillovers $q_{i}$ in this model. Within this range, sectors are then ranked ordinally according to their relative learning potential. ${ }^{12}$ Sectors that are more intensive in skilled labor will exhibit higher overall marginal productivity, higher learning capability, and higher $q_{i}$.

Undoubtedly, R\&D is one of the most skill-intensive productive activities. ${ }^{13}$ Thus, in order to proxy a sector's learning potential I use the dataset by Hadlock, Hecker and Gannon (1991) on the sectoral proportion of R\&D employment relative to the average and rank the paper's six sectors according to their $q_{i}$. All ten R\&D-moderate industries and twenty-four of the thirty R\&D-intensive industries in Hadlock et al. are in manufacturing, five are in services, and one in mining (crude petroleum and natural gas operations). Therefore manufacturing's spillover is set at a conservative maximum of 0.3 ; services and mining follow as the most knowledge absorptive sectors in the economy. The distance between sectoral spillovers is normalized at 0.05.

According to McKinsey Global Institute (2001), the US productivity jump that began in 1995 is structural in nature (i.e. due to earlier fundamental changes) and can be explained by the performance of retail, wholesale, securities, telecom services, semiconductors, and computer manufacturing. Retail and wholesale constitute a large percentage of the value added in trade \& transportation; securities and telecom are part of services; and the last two, of manufacturing. Thus, trade \& transportation ranks fourth.

Agriculture is last in the ranking because most of the research that has played a vital role in its growth has been in biotechnology and the food industry (Fuglie, MacDonald and Ball 2007), both within manufacturing. Similarly, fragmentation of the construction industry has led to low investment in R\&D (Federal Facilities

\footnotetext{
${ }^{12}$ See Lucas (1988) for a multi-sector model with different sectoral learning rates.

${ }^{13}$ See Young (1993) for a model in which the interdependence between innovation at the R\&D lab and learning by doing at the production floor determine cumulative experience and the costs of production.
} 
Council 1995).

In summary, estimates in previous literature set the value range for $q_{i}$, and each sector's relative learning potential determines its place in the general ranking of spillovers, which can be seen in Table 1. Using these sectoral values, the model's economywide knowledge spillover $Q$ comes up to be 0.23 , well within the range set by previous estimates.

\section{Learning Parameters: the Matrix of Knowledge Flows}

The last section of Table 1 records the numerical values of learning parameters $\gamma_{i j}$, expressed as percentages of the total sectoral spillover received $q_{i}$, in the form of a $6 \times 6$ matrix of intra- and inter-sectoral spillovers flowing from sectors of origin $j$ to sectors of destination $i$. Appendix A2 describes how these values were computed.

Table 1 shows that manufacturing and trade \& transportation are generating most of the knowledge that spills over to the other sectors in the economy. Services and agriculture, on the other hand, benefit from knowledge generated elsewhere but make no contribution to the economy's knowledge externality. Furthermore, all sectors receive spillovers from, at least, one other sector in the economy, but manufacturing and trade \& transportation are the only two sectors to learn exclusively from each other: $100 \%$ of the knowledge trade \& transportation benefits from is originated in manufacturing, as is construction's. In fact, all other sectors, except for services, are completely dependent on one unique source for the totality of their spillover.

Most flows occur between industry (manufacturing, mining, construction) and the tertiary sector (trade \& transportation, services). Clearly, industry is the most dynamic sector, both internally and externally, that is, industry as a whole generates and receives most flows in the matrix. As for intra-sectoral flows, manufacturing is the one and only sector to learn from its own productive experience (55\%), more so than from the rest of the economy as a whole, absorbing the remaining knowledge (45\%) from trade \& transportation. 
To fully gauge the relative importance of each sectors' knowledge emissions at the national level, consumers' preferences have to be taken into account. Each sector's share of consumer demand determines the weight it has in the economy and, hence, the overall impact of the knowledge flows it generates and receives. ${ }^{14}$ The first part of Table 2 compares relative emission of knowledge by sector: $\Gamma_{i} / Q$ is the weight of the total knowledge generated by sector $i$ benefitting the whole economy, including sector $i$ itself; the second row presents the weight of sector $i$ 's emissions to sectors other than itself, $\tilde{\Gamma}_{i}=\frac{\Gamma_{i}-\alpha_{i} \gamma_{i i}}{1-\alpha_{i}}$, in the economy's total inter-sectoral spillover, $\tilde{Q}=\sum_{i=1}^{n} \tilde{\Gamma}_{i}$.

[Insert Table 2 here]

Clearly, for the period 1948-1991 manufacturing and trade \& transportation generate most knowledge, but whereas the weight of both sectors is similar for total knowledge generated in the overall economy ( $45 \%$ and $46 \%$, respectively), trade \& transportation's outgoing flows to other sectors represent $63 \%$ of the economy's total inter-sectoral flows, compared to $27 \%$ for manufacturing. The reason is that manufacturing's outflows to the rest of the economy, although large, benefit sectors whose aggregate demand amounts to slightly over one fourth of the total (construction and trade \& transportation); whereas trade \& transportation's smaller outflows benefit the two sectors with the largest demand (manufacturing and services) which, by themselves, account for two thirds of the total demand. Therefore, knowledge generated by trade \& transportation has a larger impact in the economy, slightly so for the overall economy, noticeably so for the rest of the economy.

Mining and construction also generate spillovers for other sectors. While construction's knowledge outflows only benefit agriculture, the second smallest sector, and hence have scarce impact (1\% of the total), mining's outflows benefit services and constitute around $9 \%$ of the total spillover.

\footnotetext{
${ }^{14}$ If a sector sends large knowledge flows to sectors experiencing little demand, the final weighted spillover will be of little importance to the overall economy. In contrast, the overall importance of a small knowledge flow received by a high-demand sector will be large.
} 
These results show that knowledge outflows are concentrated in manufacturing and trade \& transportation. Other sectors are basically receivers of knowledge, generating little or no learning for the economy.

\section{Comparison}

It is instructive to compare these results with previous estimates. Bernstein (1988) estimated spillovers generated by R\&D capital (physical and human) and their private and social rates of return for seven Canadian two-digit SIC industries from 1978 through 1981. He found that intra- and inter-sectoral spillovers do affect production costs and the structure of production; he also computed the wedge between private and social rates of return to the spillover-generating input. The first three columns of Table 3 show that his results and my estimations coincide broadly. Bernstein uses industries at a more disaggregate level, which partly explains why the value of his total sectoral spillovers is below 0.2. See Section 4 for comment on column four.

\section{[Insert Table 3 here]}

Van Stel and Nieuwenhuijsen (2004) use data for six macroeconomic sectors for the Netherlands from 1987 to 1995 and, assuming geographical proximity as a necessary condition, find that inter-sectoral knowledge spillovers are particularly important in their service sector (trade, transport \& communication, financial services), whereas local competition is particularly important in the industry sector (manufacturing and construction). High extents of diversity seem to encourage spillovers from industry sectors towards service sectors. The fact that the service sector is the leader in generating knowledge spillovers could arguably be due to the fact that their time period does not include the productivity slowdown of the early seventies.

Thus, comparable estimates corroborate the existence of both intra- and intersectoral spillovers and their effect on resource allocation and production costs. 


\section{How Inefficient Is the Market?}

Given these knowledge spillovers, the market does not allocate quality-adjusted labor among sectors optimally. The wedge between social and private rates of return to labor is reflected in the sectoral residuals via the knowledge spillovers. The market inefficiency, formalized in Proposition 1, is reflected in Table 2. This table presents also the relative sectoral allocation of the inputs that do not generate spillovers, capital and intermediates, for which the market solution is already optimal.

The second part of Table 2 shows it would be optimal to increase the market's allocation of labor to manufacturing, trade \& transportation, and mining. As per Proposition 1 it is optimal to increase labor input in sectors for which relative knowl-

edge emission is above labor market share, $\frac{\Gamma_{i}}{Q}>\frac{L_{i}^{c}}{L}$. This happens in manufacturing $(0.45>0.30)$, trade \& transportation $(0.46>0.27)$, and mining $(0.08>0.02)$. Thus, it is optimal to increase labor input in manufacturing by $20 \%$ so this sector goes from employing $30 \%$ of total labor in the competitive solution to $36 \%$ in the optimal solution, maintaining its position as the largest employer in the economy and increasing its output by $12 \%$. Likewise, it is optimal to increase employment in trade \& transportation by $27 \%$, so this sector increases its share of total labor employment from $27 \%$ to $34 \%$, becoming the second employer in an efficient economy and increasing its output by $16 \%$.

Mining is such a small sector that its optimal $144 \%$ increase in employment and $29 \%$ in output have minimal impact on the overall efficiency gap. Optimal labor and output in all other sectors including construction, a spillover generating sector, and services, the second largest sector in the economy, are below market levels.

As a result, optimal wages are above (below) market rates in all sectors where optimal employment is below (above) market, except for manufacturing, where optimal employment and wage rates are both above market, the reason being that manufacturing is the only sector learning from itself, hence an optimal increase in labor 
also leads to an optimal increase in wages. ${ }^{15}$ Thus it is optimal to increase wages in manufacturing by $54 \%$ and decrease them in trade \& transportation by $12 \%$.

These results can be compared to those obtained by Bernstein (1988) and shown in the last column of Table 3. Not only does he find that spillovers create a wedge between the private and the social rates of return to the spillover-generating input, but his social-to-private ratio for all seven Canadian industries is substantially higher than mine for the whole of manufacturing. ${ }^{16}$

Summarizing, it would be optimal to redistribute quality-adjusted labor into manufacturing, trade \& transportation, and mining and away from all other sectors. As a consequence output in these sectors would increase, and wages in manufacturing, the only sector learning from its own productive experience; construction; services; and agriculture would also increase.

\section{The Seventies Slowdown: a Shift in Spillovers?}

The productivity slowdown of the early seventies has been attributed to a large number of competing reasons. Explanations range from the reduction in real company financed R\&D (Scherer 1984) to the incorrect measurement of output, particularly in services (Corrado and Slifman 1999), to an increase in the underlying rate of technological change (Greenwood and Yorukoglu 1997). Jorgenson, Gollop, and Fraumeni (1987), and Jorgenson, Ho, and Fraumeni (1994) attribute the slowdown to the stagnation of the growth in the quality of human capital derived from formal education, which would, in this model, reduce the magnitude of knowledge spillovers.

\footnotetext{
${ }^{15}$ Remember that relative optimal-to-market wages are $\frac{w_{i}^{s}}{w^{c}}=\left(1+\frac{\gamma_{i i}}{\beta_{i L}}\right) \frac{Y_{1}^{s} / Y_{1}^{c}}{L_{i}^{s} / L_{i}^{c}}$, therefore as long as sector $i$ exhibits some degree of learning-by-doing (i.e. $\gamma_{i i}>0$ ), productivity in real terms for sector $i$ will be larger in the optimal allocation of labor.

${ }^{16} \mathrm{~A}$ larger propensity to invest in R\&D capital unambiguously leads to high intra-industry spillovers, which account for most of the wedge between social and private rates of return. Whereas investing in high-quality human capital (i.e. shifting the composition of the labor input toward higher marginal productivity workers) does lead to larger intra-sectoral spillovers, $\gamma_{i i}$, but the upward impact on the social rate is dampened by the simultaneous downward pressure of higher elasticities, $\beta_{i L}$.
} 
Alternatively, we can inquire whether the slowdown is associated with changes in the creation and/or the absorption of knowledge. That is, whether sectoral spillovers shifted after 1973. To that purpose, I split data into a pre-73 and a post-73 period and calibrate learning parameters independently for each period. The results are presented in Table 4.

\section{[Insert Table 4 here]}

After 1973, manufacturing's demand is off by 6 percentage points (from $44 \%$ of total demand to $38 \%$ ), whereas services' grows by 9 points (from $21 \%$ to $30 \%$ of total demand); the remaining sectors' relative demand variations are, overall, negligible. Moreover, manufacturing's importance as a source and destination of knowledge diminishes. The number of manufacturing's knowledge outflows into the economy decrease: from mining and construction prior to the slowdown to only services after it. On the contrary, post-73 trade \& transportation emerges as the source of knowledge outflows: all sectors except services and agriculture derive the totality of spillovers from trade \& transportation. In particular, mining and construction have entirely switched the source of their inflows from manufacturing to trade \& transportation. In addition, not only is post-slowdown trade \& transportation the only sector to learn from itself: it learns only from itself.

Post-73 services and construction lose their capacity to generate knowledge, but services experiences a relative gain in learning capabilities; it diversifies its inflow sources. Prior to 1973 services only learned from trade \& transportation; post-73 it absorbs knowledge from manufacturing and mining, although not from itself.

In summary, after the slowdown the number and relative weight of sector-specific spillovers in the total diminish in favor of inter-sectoral knowledge flows. The industrial sector, in particular manufacturing, lose importance in favor of trade \& transportation as the source of knowledge for the overall economy, to the point where industry becomes completely dependent on trade \& transportation for its knowledge 
inflows. ${ }^{17}$ Specifically, after 1973, manufacturing's sector-specific spillovers disappear, whereas trade \& transportation only learns from itself.

Table 5 compares the relative weight of a sector's total spillover in the overall economy, as well as the importance of each sector's knowledge outflows to the rest of the economy before and after 1973.

\section{[Insert Table 5 here]}

Prior to the slowdown construction is the main generator of knowledge (34\% of the total), followed by manufacturing and trade \& transportation (26\% and $23 \%$ ) and, at a distance, by services (17\%). After 1973 trade \& transportation alone emits over two thirds of all spillovers, whereas manufacturing's share falls to $23 \%$, and the importance of construction and services fades altogether. Mining emerges as a new source of spillovers.

Post-1973, the weight of construction and services as a source of spillovers for other sectors also disappears. On the contrary, manufacturing appears to integrate with the rest of the economy and its $31 \%$ contribution takes second place to trade \& transportation's 59\%. Mining is the third sector to benefit other sectors with $10 \%$ of the total inter-sectoral spillover.

The second part of Table 5 shows the change in the efficiency gap before and after 1973. To begin with, employment decreases in manufacturing and increases in services in both the competitive and the optimal solution. But, whereas after 1973 the market assigns less labor to manufacturing than to services, it is still optimal to keep more employment in manufacturing than in services because $67 \%$ of services knowledge inflows originate in manufacturing (while no knowledge originates in services), and post-73 services is the only sector in the economy that has grown substantially.

As for trade \& transportation, after 1973 the market and the planner pull in opposite directions: while the market reduces the amount of labor input it allocates

\footnotetext{
${ }^{17}$ These results predate what McKinsey Global Institute (2001) found with regards to the U.S. productivity jump that began in 1995 .
} 
to this sector, it is optimal to increase it by 16 percentage points, making it the largest employer in the economy ( $42 \%$ of all labor input) and reversing the optimal-to-market labor ratio from a reduction of $8 \%$ prior to 1973 to an increase of $70 \%$ after (which results in a $39 \%$ increase in this sector's output). This is because the relative amount of knowledge trade \& transportation generates for the overall economy trebles up to $68 \%$ after 1973.

The market does not alter its labor allocation in mining, construction, and agriculture significantly after 1973, but the planner increases labor in mining and reduces it in agriculture and, especially, construction. This is because post-73 mining is generating knowledge for services, while spillovers generated by construction no longer benefit manufacturing and construction itself, but only agriculture.

Regarding wages, the optimal-to-market gap in manufacturing decreases by 37 percentage points to 1.25 after 1973 as a consequence of the loss of sector-specific learning. Construction also ceases learning from itself after the slowdown, but the reversal in the optimal-to-market employment gap more than compensates for this loss, setting optimal wages $81 \%$ above market. The exact opposite happens in trade \& transportation that, after 1973, only learns from itself but where the reversal in the optimal-to-market employment gap results in optimal wages $11 \%$ below market. As for mining, the optimal increase in employment is so large (184\%) that it pushes optimal wages to $60 \%$ below market.

In summary, after the slowdown inter-sectoral knowledge flows gain relative importance. Simultaneously, the industrial sector in general, and manufacturing in particular, lose importance in favor of trade \& transportation as the source of knowledge for the overall economy. Moreover, manufacturing's learning capability diminishes and this sector stops cumulating knowledge derived from its own innovation and productive processes. On the contrary, trade \& transportation begins applying fundamentally new processes and technologies in the delivery of products and services, which requires more skills from its workers, who move on to steeper learning curves 
and become the new source of knowledge for the overall economy. As a result, it is optimal to have trade $\&$ transportation be the main employer in the post-73 economy.

\section{Conclusions}

While there is no agreement on the exact source and form of externalities, its importance for economic growth and business cycles has been accepted; constant returns do a poor job replicating reality. Moreover, previous empirical work has found evidence on the existence of external economies operating at the national level.

In this paper I use quality-adjusted data on inputs and output at the industry level to estimate labor generated knowledge spillovers within and across industries. The purpose is to shed some light on whether knowledge diffuses across sectors when one firm's productive experience may enhance other firms' efficiency as well as its own. The source of TFP growth or productivity gains at the aggregate level is, thus, the existence of learning by observing as well as learning by doing, along the lines of Arrow (1962) and Lucas (1988).

To this purpose I establish a method to compute the learning parameters that characterize a Cobb-Douglas production function in which the employment schedule or sectoral structure of the economy determines productivity in each industry.

I find that from 1948 to 1991 the manufacturing and trade \& transportation sectors were the undisputed engines of growth for the U.S., generating knowledge for the overall economy. I also find that there is indeed a wedge between how the market allocates and rewards labor and the optimal, which disagrees with some recent stream of literature concerning geographically localized spillovers. That is, economywide market wages do not absorb the totality of the costless productivity gains generated by the spillovers. Thus, the market allocates resources inefficiently: more labor should go to sectors generating knowledge for the whole economy, so that quality-adjusted employment in manufacturing would increase by $20 \%$ and in trade \& transportation 
by $27 \%$. As a consequence, output in manufacturing would go up by $12 \%$ and in trade \& transportation by $16 \%$. Wages in all sectors, except for mining and trade \& transportation, ought to increase by, at least, 54\%, with workers in agriculture and services perceiving wages $86 \%$ above market.

Furthermore, the productivity slowdown of the early seventies coincides with a change in the pattern of generation and diffusion of knowledge. After 1973, manufacturing ceases learning from itself and integrates with the rest of the economy, whereas trade \& transportation goes on to learn only from itself. Morevoer, the capability of manufacturing to generate knowledge wanes, while trade \& transportation comes to generate over two thirds of the knowledge flows benefitting the overall economy. Simultaneously, the slowdown is associated with a decrease in the relative importance of spillovers within sectors in favor of spillovers between sectors.

The proposed framework can be extended to a dynamic setup that takes into account forward-looking decisions on investment in physical or human capital. The results presented here are encouraging about the feasibility of these extensions in future research. 


\section{Appendix}

\section{A1. Industry Classification}

The following Table presents the equivalence between the original 35-sector classification used by D. Jorgenson, the SIC (1987), and the six-sector classification used in this model. Note sector 35, Government Enterprises, has been eliminated from the final selection.

\begin{tabular}{lll}
\hline \hline D. Jorgenson & SIC (1987) & Model \\
\hline & & \\
1 Agriculture, fisheries and forestry & $01,02,07,08,09$ & $\mathrm{~A}$ \\
2 Metal mining & 10 & $\mathrm{~N}$ \\
3 Coal mining & 12 & $\mathrm{~N}$ \\
4 Oil and gas extraction & 13 & $\mathrm{~N}$ \\
5 Non-metallic mining & 14 & $\mathrm{~N}$ \\
6 Construction & $15,16,17$ & $\mathrm{C}$ \\
7 Food and kindred products & 20 & $\mathrm{M}$ \\
8 Tobacco & 21 & $\mathrm{M}$ \\
9 Textile mill products & 22 less 225 & $\mathrm{M}$ \\
10 Apparel & 23,225 & $\mathrm{M}$ \\
11 Lumber and wood & 24 less 2451 & $\mathrm{M}$ \\
12 Furniture and fixtures & 25 & $\mathrm{M}$ \\
13 Paper and allied & 26 & $\mathrm{M}$ \\
14 Printing, publishing and allied & 27 & $\mathrm{M}$ \\
15 Chemicals & 28 less 282 & $\mathrm{M}$ \\
16 Petroleum and coal products & 29 & $\mathrm{M}$ \\
17 Rubber and misc plastics & 30,282 & $\mathrm{M}$ \\
18 Leather & 31 & $\mathrm{M}$ \\
19 Stone, clay, glass & 32 & $\mathrm{M}$ \\
20 Primary metal & 33 & $\mathrm{M}$ \\
21 Fabricated metal & 34 less 348 & $\mathrm{M}$ \\
22 Machinery, non-electical & 35 & $\mathrm{M}$ \\
23 Electrical machinery & 36 & $\mathrm{M}$ \\
24 Motor vehicles & 371 & $\mathrm{M}$ \\
25 Transportation equipment \& ordnance & $348,2451,37$ less 371 & $\mathrm{M}$ \\
26 Instruments & 38 & $\mathrm{M}$ \\
27 Miscellaneous manufacturing & 39 & $\mathrm{M}$ \\
28 Transportation & 40 to 47 less 43 & $\mathrm{~T}$ \\
29 Communications & 48 & $\mathrm{~S}$ \\
30 Electric utilities & 491 & $\mathrm{~S}$ \\
31 Gas utilities & 492 & $\mathrm{~T}$ \\
32 Trade (retail and wholesale) & 50 to 59 & $\mathrm{~S}$ \\
33 Finance, insurance, and real estate (FIRE) & 60 to 67 & $\mathrm{~S}$ \\
34 Services & 70 to 89 & - \\
35 Government enterprises & 91 to 99, plus 43 & \\
\hline \hline & & \\
& &
\end{tabular}




\section{A2. Computation Procedure}

In order to recover the learning parameters I follow a strategy that assumes constant returns to scale and perfect competition, and that stems directly from the relationship between rates of growth implied by the production function:

$$
\dot{Y}_{i}=\beta_{i K} \dot{K}_{i}+\beta_{i L} \dot{L}_{i}+\beta_{i M} \dot{M}_{i}+\sum_{j=1}^{n} \gamma_{i j} \dot{L}_{j}
$$

where $\dot{Y}, \dot{K}, \dot{L}$, and $\dot{M}$ are, respectively, the growth rates of the index quantities of output, physical capital, labor inputs, and intermediate inputs.

To compute sectoral productivity growth rates I use the Tornqvist index, a discrete-time approximation to the Divisia index:

$$
\dot{\theta}_{i}=\dot{Y}_{i}-\bar{S}_{i K} \dot{K}_{i}-\bar{S}_{i L} \dot{L}_{i}-\bar{S}_{i M} \dot{M}_{i}
$$

where $\dot{\theta}_{i}$ is the growth rate of TFP for sector $i$ in terms of the differences of natural logarithms, and $\bar{S}_{i K}, \bar{S}_{i L}$, and $\bar{S}_{i M}$ are the average between-period cost-shares and output elasticities of each input. Thus, we can rewrite this equation as:

$$
\dot{\theta}_{i}=\sum_{j=1}^{n} \gamma_{i j} \dot{L}_{j}
$$

that is, actual (observed) productivity growth equals productivity growth predicted by the model's production function. The variation of the residual associated to sector $i$ is the sum of each sector's variation in employment weighted by sector $i$ 's learning parameters or absorptive capacity. It measures the costless gains to sector $i$ from the overall employment scheme. Hence, the residual is not a non-parametric estimation of a fixed parameter of the production function, but the reflection of a process.

To recover the learning parameters I minimize the distance between predicted and observed TFP growth, subject to the calibrated values of $q_{i}$ and to a non-negativity constraint. The problem is then to choose parameters $\gamma_{i 1}, \gamma_{i 2}, \ldots, \gamma_{i n}, \forall i=1,2, \ldots, n$, to

$$
\begin{aligned}
& \min \sum_{t=1}^{\bar{t}}\left[\dot{\theta}_{i t}-\sum_{j=1}^{n} \gamma_{i j} \dot{L}_{j t}\right]^{2}, \\
& \text { subject to } \\
& q_{i}=\sum_{j=1}^{n} \gamma_{i j} \text { and } \gamma_{i j} \geq 0, \forall i, j .
\end{aligned}
$$

Each coefficient will measure how much productive knowledge flows within or between sectors, given the sectoral allocation of labor. ${ }^{18}$

\footnotetext{
${ }^{18}$ Because $A_{i}$ is time-invariant it is absent in the right hand side of the equation relating actual and predicted productivity growth. In consequence, these are non-intercept estimations and the Rsquare statistic does not produce valuable information about goodness of fit: the sum of the squared errors may exceed the total sum of squares (Casella 1983, Kvalseth 1985).
} 


\section{References}

Arrow, K. (1962), 'The Economic Implications of Learning by Doing', Review of Economic Studies 29, 155-173.

Bartelsman, E., Caballero, R. and Lyons, R. (1991), Short and Long Run Externalities. NBER Working Paper No. W3810.

Bartelsman, E., Caballero, R. and Lyons, R. (1994), 'Customer- and Supplier-Driven Externalities', The American Economic Review 84(4), 1075-1084.

Baxter, M. and King, R. (1991), Productive Externalities and Business Cycles. Federal Reserve Bank of Minneapolis, Institute for Empirical Macroeconomics, Discussion Paper No. 53.

Benhabib, J. and Jovanovic, B. (1991), 'Externalities and Growth Accounting', The American Economic Review 81(1), 82-113.

Bernstein, J. (1988), 'Costs of Production, Intra- and Interindustry R\&D Spillovers: Canadian Evidence', Canadian Journal of Economics 2, 324-347.

Caballero, R. and Lyons, R. (1992), 'External Effects in U.S. Procyclical Productivity', Journal of Monetary Economics 29(2), 209-225.

Casella, G. (1983), 'Leverage and Regression Through the Origin', The American Statistician $\mathbf{3 7}(2)$, 147-152.

Cohen, W. and Levinthal, D. (1990), 'Absorptive Capacity: A New Perspective on Learning and Innovation', Administrative Science Quarterly 35, 128-152.

Corrado, C. and Slifman, L. (1999), 'Decomposition of Productivity and Unit Costs', The American Economic Review 89(2), 328-332.

Domowitz, I., Hubbard, R. and Petersen, J. (1988), 'Market Structure and Cyclical Fluctuations in U.S. Manufacturing', Review of Economics and Statistics 70(1), 55-66.

Federal Facilities Council (1995), Federal Policies to Foster Innovation and Improvement in Constructed Facilities: Summary of a Symposium. Technical Report No. 129.

Fuglie, K. O., MacDonald, J. M. and Ball, E. (2007), Productivity Growth in U.S. Agriculture. Economic Brief No. 9, United States Department of Agriculture Economic Research Service.

Greenwood, J. and Yorukoglu, M. (1997), '1974', Carnegie-Rochester Conference Series on Public Policy 46, 49-95.

Hadlock, P., Hecker, D. and Gannon, J. (1991), 'High Technology Employment: Another View', Monthly Labor Review 7, 26-30.

Hall, R. (1988), 'The Relation Between Price and Marginal Cost in the U.S. Industry', Journal of Political Economy 96(5), 921-947.

Hall, R. (1990), Invariance Properties of Solow's Productivity Residual, in P. Diamond, ed., 'Growth, Productivity, Unemployment', MIT Press, Cambridge. 
Jorgenson, D. W. (1990), Productivity and Economic Growth, in Ernst R. Berndt and Jack E. Triplett, eds, 'Fifty Years of Economic Measurement: The Jubilee Conference on Research in Income and Wealth', University of Chicago Press, Chicago, IL.

Jorgenson, D. W., Gollop, F. and Fraumeni, B. (1987), Productivity and U.S. Economic Growth, Harvard University Press, Cambridge, MA.

Jorgenson, D. W. and Griliches, Z. (1967), 'The Explanation of Productivity Change', Review of Economic Studies 34, 249-280.

Jorgenson, D. W., Ho, M. and Fraumeni, B. (1994), The Quality of the U.S. Workforce, 1948-90. Cambridge, NBER Summer Institute on Productivity.

Jorgenson, D. W. and Stiroh, K. J. (2000), 'Raising the Speed Limit: U.S. Economic Growth in the Information Age', Brookings Papers on Economic Activity 1, 125-211.

Jovanovic, B. and Nyarko, Y. (1995), 'The Transfer of Human Capital', Journal of Economic Dynamics and Control 19(5), 1033-1064.

Jovanovic, B. and Rousseau, P. (2002), 'Moore's Law and Learning by Doing', Review of Economic Dynamics 5, 346-375.

Klenow, P. (1998), 'Learning Curves and the Cyclical Behavior of Manufacturing Industries', Review of Economic Dynamics 1, 531-550.

Klump, R., McAdam, P. and Willman, A. (2007), 'Factor Substitution and FactorAugmenting Technical Progress in the United States: A Normalized Supply-Side System Approach', Review of Economics and Statistics 89(1), 183-192.

Kvalseth, T. O. (1985), 'Cautionary Note about R2', The American Statistician 39(4), 279285.

Lieberman, M. (1984), 'The Learning Curve and Pricing in the Chemical Processing Industries', Rand Journal of Economics 15, 213-228.

Long, J. and Plosser, C. (1983), 'Real Business Cycles', Journal of Political Economy 91(1), 39-69.

Lucas, R. E. (1988), 'On the Mechanics of Economic Development', Journal of Monetary Economics 22(1), 3-42.

Lucas, R. E. (1993), 'Making a Miracle', Econometrica 61(2), 251-272.

McKinsey Global Institute (2001), US Productivity Growth: 1995-2000. McKinsey and Company, Inc.

Rapping, L. (1965), 'Learning and World War II Production Functions', Review of Economics and Statistics 47(1), 81-86.

Scherer, F. (1984), Using Linked Patent and R\&D Data to Measure Interindustry Technology Flows, in Z. Griliches, ed., 'R\&D, Patents, and Productivity', University of Chicago Press, Chicago.

Thompson, P. (2006), 'Patent Citations and the Geography of Knowledge Spillovers: Evidence from Inventor- and Examiner-Added Citations', Review of Economics and Statistics 88(2), 383-388. 
van Stel, A. and Nieuwenhuijsen, H. (2004), 'Knowledge Spillovers and Economic Growth: An Analysis Using Data of Dutch Regions in the Period 1987-1995', Regional Studies 38, 393-407.

Young, A. (1993), 'Invention and Bounded Learning by Doing', Journal of Political Economy 101(3), 443-472. 
Table 1: Calibrated Parameters, 1948-1991

\begin{tabular}{|c|c|c|c|c|c|c|c|c|}
\hline \multirow[t]{2}{*}{ Parameter } & & \multicolumn{6}{|c|}{ Value } & \multirow[t]{2}{*}{ Target } \\
\hline & $i=$ & $\bar{M}$ & $\mathbf{N}$ & $\mathbf{C}$ & $\mathbf{S}$ & $\mathbf{T}$ & $\mathbf{A}$ & \\
\hline \multicolumn{9}{|c|}{ Consumers' Preferences } \\
\hline$\alpha_{i}$ & & 0.41 & 0.03 & 0.08 & 0.24 & 0.18 & 0.05 & $\bar{Y} / Y$ \\
\hline \multicolumn{9}{|c|}{ Technology } \\
\hline$\overline{\boldsymbol{\beta}_{i K}}$ & & 0.09 & 0.36 & 0.08 & 0.26 & 0.15 & 0.15 & \\
\hline $\boldsymbol{\beta}_{i L}^{i N}$ & & 0.25 & 0.23 & 0.37 & 0.39 & 0.51 & 0.27 & $w_{x_{i}} X_{i} / P_{i} Y_{i}$ \\
\hline $\boldsymbol{\beta}_{i M}$ & & 0.65 & 0.41 & 0.55 & 0.34 & 0.34 & 0.58 & $X=K, L, M$ \\
\hline \multicolumn{9}{|c|}{ Spillovers } \\
\hline $\mathbf{q}_{i}$ & & 0.30 & 0.20 & 0.10 & 0.25 & 0.15 & 0.05 & Literature \\
\hline \multicolumn{9}{|c|}{ Learning Parameters $^{a}$} \\
\hline & $j=$ & & & & & & & \multirow{7}{*}{$\dot{\theta}_{i}$} \\
\hline & $\mathbf{M}$ & 0.55 & 0 & 1.00 & 0 & 1.00 & 0 & \\
\hline & $\mathbf{N}$ & 0 & 0 & 0 & 0.30 & 0 & 0 & \\
\hline & $\mathrm{C}$ & 0 & 0 & $\mathbf{0}$ & 0 & 0 & 1.00 & \\
\hline$\gamma_{i j} / \mathbf{q}_{i}$ & $\mathbf{S}$ & 0 & 0 & 0 & $\mathbf{0}$ & 0 & 0 & \\
\hline & $\mathbf{T}$ & 0.45 & 1.00 & 0 & 0.70 & $\mathbf{0}$ & 0 & \\
\hline & A & 0 & 0 & 0 & 0 & 0 & 0 & \\
\hline
\end{tabular}

$a$. Rows are sectors of origin $j$, columns are sectors of destination $i$.

$i, j=M, N, C, S, T, A$, where $M=$ manufacturing; $N=$ mining; $C=$ construction; $S=$ services;

$T=$ trade $\&$ transportation; and $A=$ agriculture. 
Table 2: Market Inefficiency, 1948-1991

\begin{tabular}{|c|c|c|c|c|c|c|}
\hline & $\overline{\bar{M}}$ & $\overline{\mathbf{N}}$ & $\overline{\mathbf{C}}$ & $\overline{\bar{S}}$ & $\overline{\bar{T}}$ & $\overline{\bar{A}}$ \\
\hline \multicolumn{7}{|c|}{ Relative Spillover } \\
\hline $\boldsymbol{\Gamma}_{i} / \mathbf{Q}$ & 0.45 & 0.08 & 0.01 & 0 & 0.46 & 0 \\
\hline$\tilde{\boldsymbol{\Gamma}}_{i} / \tilde{\mathbf{Q}}$ & 0.27 & 0.09 & 0.01 & 0 & 0.63 & 0 \\
\hline \multicolumn{7}{|c|}{ Market and Optimal Solutions ${ }^{a}$} \\
\hline $\mathbf{L}_{i}^{c} / \mathbf{L}$ & 0.30 & 0.02 & 0.09 & 0.28 & 0.27 & 0.04 \\
\hline $\mathbf{L}_{i}^{s} / \mathbf{L}$ & 0.36 & 0.04 & 0.06 & 0.17 & 0.34 & 0.02 \\
\hline $\mathbf{L}_{i}^{s} / \mathbf{L}_{i}^{c}$ & 1.20 & 2.44 & 0.65 & 0.60 & 1.27 & 0.60 \\
\hline $\mathbf{Y}_{i}^{s} / \mathbf{Y}_{i}^{c}$ & 1.12 & 1.29 & 0.87 & 0.91 & 1.16 & 0.85 \\
\hline $\mathbf{w}_{i}^{s} / \mathbf{w}^{c}$ & 1.54 & 0.46 & 1.72 & 1.86 & 0.88 & 1.86 \\
\hline \multicolumn{7}{|c|}{ Common to Market and Optimal Solutions } \\
\hline $\mathbf{K}_{i} / \mathbf{K}$ & 0.25 & 0.06 & 0.04 & 0.42 & 0.18 & 0.05 \\
\hline $\mathbf{M}_{i} / \mathbf{M}$ & 0.53 & 0.02 & 0.09 & 0.17 & 0.12 & 0.06 \\
\hline
\end{tabular}

a. Manufacturing is the numeraire.

Table 3: Bernstein's Knowledge Spillovers for Canada, 1978-1981

\begin{tabular}{lcccc}
\hline \hline \multirow{2}{*}{$\begin{array}{l}\text { Sector of } \\
\text { Destination (i) }\end{array}$} & \multicolumn{3}{c}{ Knowledge Spillovers } & \multicolumn{2}{c}{$\begin{array}{c}\text { Social to Private } \\
\text { Rates of Return }\end{array}$} \\
\cline { 2 - 4 } & $\begin{array}{c}\text { Intra-sec. } \\
\gamma_{i i}^{s} / q_{i}\end{array}$ & $\begin{array}{l}\text { Inter-sec. } \\
\sum \gamma_{i j} / q_{i}\end{array}$ & $\begin{array}{c}\text { Total } \\
q_{i}\end{array}$ & \begin{tabular}{c}
$q_{i} / \omega^{c}$ \\
\hline Chemical Products
\end{tabular} \\
\hline \hline & 0.84 & 0.16 & 0.148 & 2.27 \\
Electrical Products & 0.84 & 0.16 & 0.141 & 2.22 \\
Aircraft \& Parts & 0.81 & 0.19 & 0.114 & 1.98 \\
Pulp \& Paper & 0.81 & 0.19 & 0.088 & 1.76 \\
Metal Fabricating & 0.75 & 0.25 & 0.086 & 1.74 \\
Food \& Beverage & 0.77 & 0.23 & 0.084 & 1.72 \\
Non-electrical Machinery & 0.71 & 0.29 & 0.077 & 1.66 \\
& & & & \\
\hline \hline
\end{tabular}

a. $\omega^{c}=0.1162$ for all industries. 
Table 4: Calibrated Parameters, Pre- and Post-1973

\begin{tabular}{|c|c|c|c|c|c|c|c|c|c|c|c|c|c|}
\hline \multirow[t]{3}{*}{ Param. } & & \multicolumn{12}{|c|}{$\overline{\text { Value }}$} \\
\hline & \multirow[t]{2}{*}{$i=$} & \multicolumn{2}{|c|}{$\bar{M}$} & \multicolumn{2}{|c|}{$\mathbf{N}$} & \multicolumn{2}{|c|}{$\mathrm{C}$} & \multicolumn{2}{|c|}{$\mathrm{S}$} & \multicolumn{2}{|c|}{$\mathbf{T}$} & \multicolumn{2}{|c|}{$\mathbf{A}$} \\
\hline & & Pre & Post & Pre & Post & Pre & Post & Pre & Post & Pre & Post & Pre & Post \\
\hline \multicolumn{14}{|c|}{ Consumers' Preferences } \\
\hline$\alpha_{i}$ & & 0.44 & 0.38 & 0.02 & 0.03 & 0.09 & 0.08 & 0.21 & 0.30 & 0.19 & 0.18 & 0.06 & 0.04 \\
\hline \multicolumn{14}{|c|}{ Technology } \\
\hline $\boldsymbol{\beta}_{i K}$ & & 0.10 & 0.09 & 0.36 & 0.36 & 0.07 & 0.08 & 0.29 & 0.23 & 0.16 & 0.13 & 0.14 & 0.17 \\
\hline $\boldsymbol{\beta}_{i L}$ & & 0.26 & 0.24 & 0.24 & 0.22 & 0.36 & 0.39 & 0.39 & 0.39 & 0.54 & 0.47 & 0.29 & 0.24 \\
\hline $\boldsymbol{\beta}_{i M}$ & & 0.64 & 0.67 & 0.40 & 0.42 & 0.57 & 0.53 & 0.32 & 0.38 & 0.30 & 0.39 & 0.57 & 0.59 \\
\hline \multicolumn{14}{|c|}{ Spillovers } \\
\hline $\mathbf{q}_{i}$ & & 0.30 & 0.30 & 0.20 & 0.20 & 0.10 & 0.10 & 0.25 & 0.25 & 0.15 & 0.15 & 0.05 & 0.05 \\
\hline \multicolumn{14}{|c|}{ Learning Parameters $^{a}$} \\
\hline \multirow{6}{*}{$\gamma_{i j} / \mathbf{q}_{i}$} & $\begin{array}{l}j= \\
\mathbf{M}\end{array}$ & 0.39 & 0 & 1 & 0 & 0.49 & 0 & 0 & 067 & 0 & 0 & 0 & 0 \\
\hline & $\mathbf{N}$ & $\mathbf{0}$ & 0 & $\mathbf{0}$ & 0 & $\mathbf{0}$ & 0 & $\mathbf{0}$ & 0.33 & 0 & 0 & 0 & 0 \\
\hline & C & 0.33 & 0 & 0 & 0 & 0.51 & 0 & 0 & 0 & 1 & 0 & 0 & 1 \\
\hline & $\mathbf{S}$ & 0.27 & 0 & 0 & 0 & 0 & 0 & 0 & 0 & 0 & 0 & 1 & 0 \\
\hline & $\mathbf{T}$ & 0 & 1 & 0 & 1 & 0 & 1 & 1 & 0 & 0 & 1 & 0 & 0 \\
\hline & A & 0 & 0 & 0 & 0 & 0 & 0 & 0 & 0 & 0 & 0 & 0 & 0 \\
\hline
\end{tabular}

$a$. Rows are sectors of origin $j$, columns are sectors of destination $i$.

$i, j=M, N, C, S, T, A$, where $M=$ manufacturing; $N=$ mining; $C=$ construction;

$S=$ services; $T=$ trade $\&$ transportation; and $A=$ agriculture. 
Table 5: Sectoral Spillovers and Input Allocation, Pre- and Post-1973

\begin{tabular}{|c|c|c|c|c|c|c|c|c|c|c|c|c|}
\hline & \multicolumn{2}{|c|}{$\overline{\mathrm{M}}$} & \multicolumn{2}{|c|}{$\mathbf{N}$} & \multicolumn{2}{|c|}{$\mathbf{C}$} & \multicolumn{2}{|c|}{$\mathbf{S}$} & \multicolumn{2}{|c|}{$\mathbf{T}$} & \multicolumn{2}{|c|}{$\mathbf{A}$} \\
\hline & Pre & Post & Pre & Post & Pre & Post & Pre & Post & Pre & Post & Pre & Post \\
\hline \multicolumn{13}{|c|}{ Relative Emission of Spillovers: Total and Inter-Sectoral } \\
\hline $\boldsymbol{\Gamma}_{i} / \mathbf{Q}$ & 0.26 & 0.23 & $\mathbf{0}$ & 0.09 & 0.34 & 0 & 0.17 & 0 & 0.23 & 0.68 & $\mathbf{0}$ & 0 \\
\hline$\tilde{\boldsymbol{\Gamma}}_{i} / \tilde{\mathbf{Q}}$ & 0.06 & 0.31 & $\mathbf{0}$ & 0.10 & 0.40 & 0.01 & 0.24 & 0 & 0.30 & 0.59 & $\mathbf{0}$ & 0 \\
\hline \multicolumn{13}{|c|}{ Market and Optimal Solutions $^{a}$} \\
\hline $\mathbf{L}_{i}^{c} / \mathbf{L}$ & 0.33 & 0.27 & 0.02 & 0.02 & 0.09 & 0.09 & 0.23 & 0.35 & 0.29 & 0.25 & 0.05 & 0.03 \\
\hline $\mathbf{L}_{i}^{s} / \mathbf{L}$ & 0.30 & 0.25 & 0.01 & 0.05 & 0.19 & 0.06 & 0.20 & 0.21 & 0.26 & 0.42 & 0.03 & 0.02 \\
\hline $\mathbf{L}_{i}^{s} / \mathbf{L}_{i}^{c}$ & 0.91 & 0.92 & 0.61 & 2.84 & 2.04 & 0.63 & 0.89 & 0.60 & 0.92 & 1.70 & 0.64 & 0.60 \\
\hline $\mathbf{Y}_{i}^{s} / \mathbf{Y}_{i}^{c}$ & 1.03 & 1.15 & 0.87 & 1.40 & 1.33 & 0.88 & 0.94 & 0.88 & 1.06 & 1.39 & 0.88 & 0.86 \\
\hline $\mathbf{w}_{i}^{s} / \mathbf{w}^{c}$ & 1.62 & 1.25 & 1.71 & 0.40 & 0.58 & 1.81 & 1.16 & 1.93 & 1.13 & 0.89 & 1.61 & 1.93 \\
\hline \multicolumn{13}{|c|}{ Common to Market and Optimal Solutions } \\
\hline$\overline{\mathbf{K}_{i} / \mathbf{K}}$ & 0.28 & 0.23 & 0.06 & 0.07 & 0.04 & 0.04 & 0.38 & 0.46 & 0.19 & 0.16 & 0.05 & 0.04 \\
\hline $\mathbf{M}_{i} / \mathbf{M}$ & 0.56 & 0.49 & 0.02 & 0.02 & 0.10 & 0.08 & 0.13 & 0.22 & 0.11 & 0.14 & 0.07 & 0.05 \\
\hline
\end{tabular}

a. Manufacturing is the numeraire. 